\title{
Optimization of the design and technological parameters of an active ripper of a combined working body
}

\author{
S. A. Ivanaisky, M. A. Kanaev*, Y. A. Kirov, M. S. Ivanaisky, S. V. Denisov
}

Samara State Agrarian University, Kinel, Samara region, 446442, Russia

\begin{abstract}
The research objective is to improve the quality of soil loosening using combined working bodies for surface moisture-retaining soil cultivation. The efficiency of accumulation and conservation of precipitation in the autumn-winter period depends on the method of post-harvest soil cultivation. One of them is the autumn surface water-retaining treatment, which makes it possible to increase the efficiency of the processes of accumulation and conservation of moisture due to the deeper loosening of the cultivated soil layer. During loosening and mulching, the top layer of the soil contributes to the accumulation and preservation of moisture not only in the upper but also in deeper soil horizons. However, the used tillage tools do not fully solve the problem of the high-quality performance of surface moisture-retaining soil cultivation. The article presents the results of studies of the degree of influence of geometric and technological parameters of the additional active cultivator on the quality of surface tillage. Based on the results of the research carried out, the technological process of performing the surface tillage operation has been improved and combined working bodies have been developed for its implementation.
\end{abstract}

\section{Introduction}

As an alternative to the main, deep tillage since autumn, cultivation is often used in recent years - the cultivation of the upper soil layer $5-12 \mathrm{~cm}$ and deeper without turning the layer. In this case, it is usually carried out after stubble cultivation; It is intended for weed control, loosening, and soil preparation for the next season. After cultivation, aeration is enhanced, the warming up of the soil is accelerated, better conditions are created for the accumulation of nutrients in an assimilable form for plants, an infestation of crops, and infection with pests and pathogens of crops is reduced. [1]

Continuous cultivators are mainly used in preparing the soil for growing crops, in clean fallow, and weed control after early harvest crops. Universal cultivators are used for both continuous and inter-row cultivation. $[2,9,10]$

Paw cultivators are used for cutting weeds and loosening the soil by $5-12 \mathrm{~cm}$. Their working bodies are paws of various designs. To loosen the soil, cultivators with coarse paws are used, and weeds are cut with extirpatory ones. In order not to reduce the quality of cultivation, it is necessary to sharpen the paws every 20 hours of work. After 5-6 hours of work, paws cut off $90 \%$ of weeds, and after 20 hours - only $60 \%$. Paw cultivators work poorly on fields clogged with rhizome weeds (they do not cut them, but wind them around their paws). [3]

Spring cultivators have paws bent in the form of strips, which during operation are capable of vibrating, which protects them from breakage. They loosen and mix the soil well and can extract rhizomes from it. Spring cultivators are widely used in the cultivation of stony soils and newly developed forest areas. [3]

Blade cultivators spray the soil much less than spring cultivators and cut the weeds deeper. They are most used in dry areas.

For deeper loosening of the soil, a chisel cultivator is used, which has several forms of working bodies (paws) attached to the frame in several rows and at different depths. It can loosen up to $30 \mathrm{~cm}$ or more without wrapping and spraying the soil hard. In the nonchernozem zone, the chisel cultivator can be used instead of plowing the soil, where necessary, in spring or summer. $[4,7,8]$

On widespread cultivators, the versatile lancet and flat-cut lancet shares are used. They are used both for continuous cultivation and for inter-row cultivation. The share equally well loosens the soil and destroys weeds, while it has an opening angle between the cutting edges of the blades of 60 and 650 , it is designed to loosen the soil to a depth of $12 \mathrm{~cm}$.

Chisel-shaped loosening shares are used to loosen solid soil to a depth of $16 \mathrm{~cm}$. The toe of the strut bent forward ends with a pointed chisel $20 \mathrm{~mm}$ wide. The chisel share is well deepened even on highly compacted soil, deforms and loosens the soil layer wider than the toe width (up to $120 \ldots 160 \mathrm{~mm}$ ).

There are also various designs and patented inventions of various working bodies that combine a combination of various undercutting wings of swept arms and loosening chisel rippers.

\footnotetext{
* Corresponding author: kanaev_miha@mail.ru
} 
This information on the means of mechanization for soil cultivation made it possible to identify ways for their improvement. One of the promising areas is the joint use of duckfoot paws with additional loosening working bodies for the effective crumbling of the treated layer, which allows increasing the accumulation and preservation of moisture.

Considering the advantages and characteristics of the existing working bodies, the Samara State Agrarian University developed and manufactured a tillage unit based on the 8000 series cultivator manufactured by Great Plains Agro LLC. The cultivator was equipped with improved combined working bodies with active chisel-shaped cultivators. [5.6]

The use of combined working bodies will allow obtaining a new unit with improved characteristics, as well as reducing production costs and increasing the competitiveness of products.

\section{Materials and methods}

One of the main tasks of the autumn surface waterretaining tillage is to create conditions in the cultivated soil layer for the complete collection and conservation of moisture. To solve this problem, it is necessary to create a qualitatively loosened soil layer with stubble residues partially embedded in it and carry out its subsurface loosening.

A loosened soil layer will allow moisture to be fully infiltrated through it, prevent evaporation from the surface of the field as much as possible, and transport moisture to deeper layers.

The technological process of the working body for the autumn surface water-retaining tillage is shown in Figure 1.

Initially, the soil layer is cut to a depth of $0.10 \mathrm{~m}$, and its quality crumbling (Figure 1).

Further, stubble residues are embedded in the surface layer of the soil (Figure 1) with simultaneous subsurface belt loosening to a depth of $0.14 \mathrm{~m}$.

This treatment will allow to completely absorb the incoming moisture due to the increased specific absorbing and transporting surface of the qualitatively loosened topsoil layer containing stubble residues distributed throughout the volume of this layer. At the same time, stubble residues provide increased protection of the surface of the treated soil layer from moisture evaporation.

After saturation of the surface layer, moisture is transported into the deeper layers of the soil, through the loosened belts of the subsurface layer. The moisture reserve created by the top layer with an effective transport and retention capacity will ensure its absorption into the deeper soil layers.

The combined working body includes duckfoot shares in its design and a ripper mounted directly on the spring rack using a special bracket located above the foot. The ripper is made in the form of a chisel with a variable crumbling angle over the entire working surface. With the help of a special bracket, you can move the ripper shank relative to the duckfoot share, which allows you to set the optimal loosening depth depending on the soil condition of the cultivated area. Moving the bracket along the spring support of the duckfoot share makes it possible to change the angle of entry of the bit from 0 to 5 degrees relative to the horizontal plane.

To perform the autumn surface water-retaining tillage to improve the quality of the technological process, a combined working body was designed and manufactured.

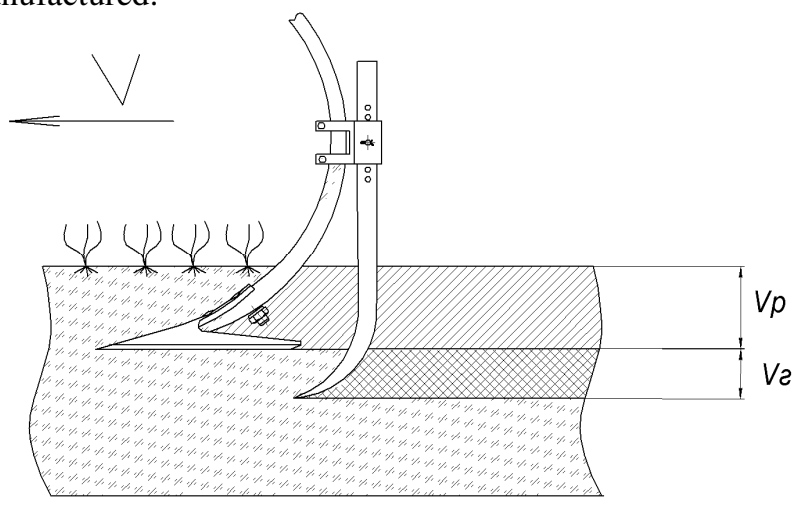

Fig. 1. Technological process of autumn surface waterretaining tillage

A cultivator with combined working bodies (Figure 2) contains a frame 5 with support-copying wheels 3 , a short tongue for aggregation with a tractor 6 , combined working bodies in the form of duckfoot paws with a ripper 2 , installed in four rows across the entire working width in four rows on the frame 5, rippers 4 are fixed directly on the rack of the duckfoot share, spring-loaded sealing rods 1 with the possibility of depth adjustment and a loading mechanism.

The technological process of the cultivator with combined working bodies is carried out in the following sequence.

Depending on the condition and type of the cultivated soil, it is necessary to set the depth of travel of the lancet paws of the combined working bodies with the help of support-gauge wheels, and then set the depth of loosening and the angle of entry into the soil of additional loosening working bodies using a special mounting bracket.

During the movement of the unit across the field, the lancet paws cut and crumble the soil layer to a predetermined depth, at the same time cutting the rhizomes of weeds and mixing stubble residues in the surface layer, creating a mulching layer for accumulating and retaining moisture. Next, the lower soil layer is loosened with a chisel-shaped working body to a great depth to create loosened strips that exclude the subsurface runoff of water and the effective penetration of the latter into the underlying soil layers to increase moisture accumulation in the matt layer.

Thus, during shallow soil cultivation, a qualitatively loosened layer with stubble residues and subsurface loosened strips is created, which, due to their increased permeability and moisture capacity, increases the penetration of atmospheric precipitation into the soil and reduces moisture loss for evaporation in comparison with traditional cultivation technology. 


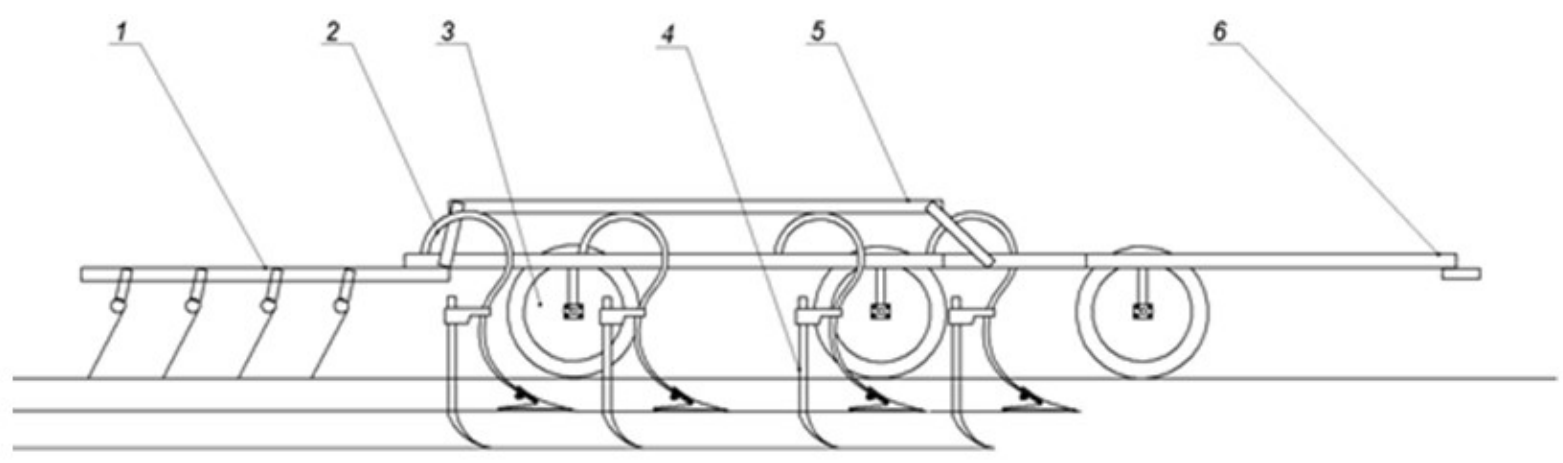

Fig. 2. 1 - sealing rods; 2 - combined working body lancet paws with a ripper; 3 - support and gauge wheels; 4 - chisel ripper; 5 frame; 6 -short tongue

The results of the theoretical and experimental studies made it possible to develop an experimental tillage tool, consisting of a serial cultivator equipped with combined working bodies, which was aggregated with a John Deere 8335R tractor to substantiate the geometric parameters and the angle of entry of the chisel-shaped working body during autumn processing.

During the research, a field site was selected that has characteristics typical for the Middle Volga region: soil type - ordinary chernozem, medium loamy, fine-crumbly structure, weakly expressed microrelief.

To determine the degree of influence of the geometric and technological parameters of the additional loosening working body on the volume of the formed furrow, experimental studies were carried out to substantiate the width, angle of entry, and depth of stroke of the bits. These studies were carried out at a constant speed of movement of the arable unit of $2.24 \mathrm{~m}$ / s.

To substantiate the width of the bit of the additional loosening working body, measurements were made of the volume of soil loosened by the bit when it was moved at one meter along the trajectory of movement, followed by recalculation to an area of 1 ha.

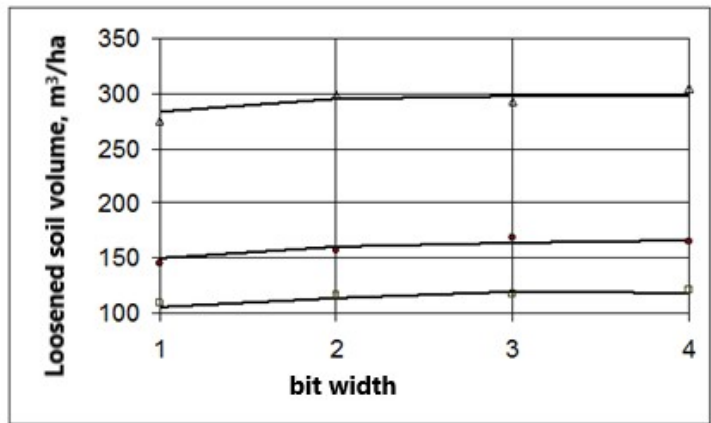

Fig. 3. Dependence of the volume of loosened soil on the bit width.

口 - bit stroke depth $0.1 \mathrm{~m}$

$\diamond$ - bit stroke depth $0,12 \mathrm{~m}$

$\Delta$ - bit stroke depth $0,14 \mathrm{~m}$

The volume of the loosened soil was determined by measuring the length of the investigated furrow and its cross-sectional area after the excavation of the loosened soil.

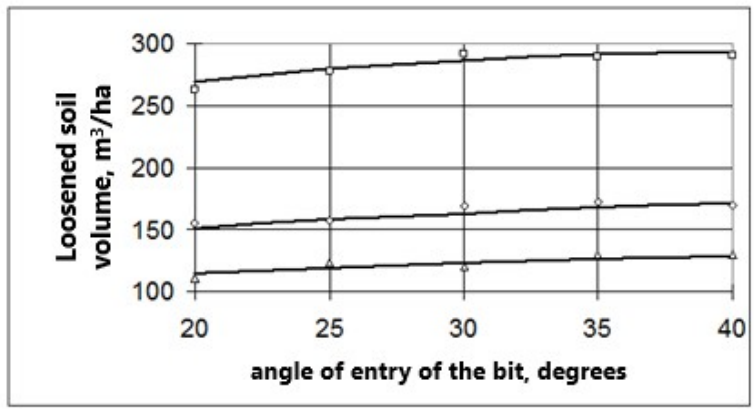

Fig. 4. Dependence of the volume of loosened soil on the angle of entry of the bit.

口 - bit stroke depth $0,1 \mathrm{~m}$

$\checkmark$ - bit stroke depth $0,12 \mathrm{~m}$

$\Delta$ - bit stroke depth $0,14 \mathrm{M}$

From the data obtained, with an increase in the bit width, there is a constant increase in the volume of loosened soil due to a constant increase in the furrow width.

\section{Results}

The results of measurements showed that with an increase in the width of the installed bit to $0.02 \mathrm{~m}$, the volume of the loosened furrow increases along a parabola (Figure 3). A slight decrease in the increase in the volume of the loosened furrow when installing bits with a width of more than $0.02 \mathrm{~m}$ is explained by the fact that during the operation of the additional loosening working body, a partial overlap of the made furrows occurs, which grows with an increase in the width of the bit. At the same time, there is a decrease in the height of the wall of not loosened soil separating adjacent furrows, precisely in the place of the greatest accumulation of water. For this reason, there is a rapid overflow of the furrow and the overflow of water into the lower furrow, along the slope, etc. This indicates the need to use a bit with a width of no more than $0.02 \mathrm{~m}$ as an active working body.

When determining the dependence of the change in the volume of loosened soil on the change in the angle of entry of the bit, the experiments were carried out by fixing the stroke depth at three levels: curve No. 1

\footnotetext{
*Corresponding author: kanaev_miha@mail.ru
} 
corresponds to a stroke depth of $0.1 \mathrm{~m}$; No. 2 - $0.12 \mathrm{~m}$ and No. $3-0.14 \mathrm{~m}$ in all variants of experiments, the angle of entry was changed from 20 to 40 degrees with a step of 5 degrees (Figure 4).

With an increase in the angle of entry of the bit of the working body by 5 degrees, the volume of soil loosened by it increases by 2.3 percent. This indicates an insignificant effect of the change in the angle of entry on the volume of the loosened furrow, even though this characteristic has a significant effect on the quality of soil crumbling. Therefore, its value, based on the requirements for the quality of soil crumbling, must be taken equal to 35 degrees.

The quality of soil crumbling during the operation of the investigated working body will be determined by the optimal design angles of crumbling of the additional loosening working body.

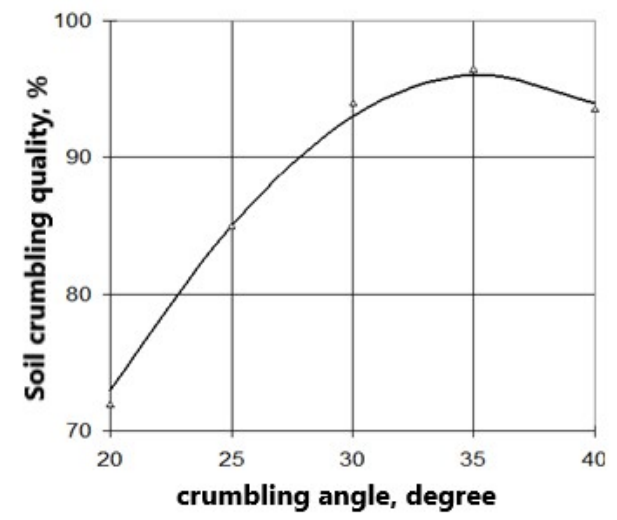

Fig. 5. Dependence of the quality of soil crumbling by the combined working body on the crumbling angle of the loosening working body

To determine the optimal value of the crumbling angle, experimental studies were carried out to determine their influence on the quality of soil crumbling at a processing depth of $0.14 \mathrm{~m}$, with operating speeds of 2; 2.25 and $2.5 \mathrm{~m} / \mathrm{s}$. The crumbling angle of the loosening working body varied from $20^{\circ}$ to $40^{\circ}$.

Analyzing the data obtained during the experiment, it can be noted that the quality of soil crumbling by a loosening working body at values of more than $90 \%$ is observed at crumbling angles from $28^{\circ}$ to $40^{\circ}$ with a maximum at $35^{\circ}$ (Figure 4).

The optimal parameters of the angle of crumbling of duckfoot paws with a loosening working body when cultivating the soil to a depth of $0.14 \mathrm{~m}$ are angle $\alpha 1=$ 350 at a working speed $v=2.24 \ldots 2.26 \mathrm{~m} / \mathrm{s}$, which ensures the quality of soil crumbling up to $95 \%$ at autumn surface moisture-retaining treatment.

To substantiate the optimal value of the distance of setting the loosening working body behind the duckfoot to create a mulching layer of soil at a depth of $0.14 \mathrm{~m}$, studies were carried out to determine the effect of the installation distance of the loosening working body behind the winged share on the degree of incorporation of stubble residues. For research, brackets were used with a distance from the strut of the duckfoot to the strut of the loosening working body of 100, 150, and $200 \mathrm{~mm}$.

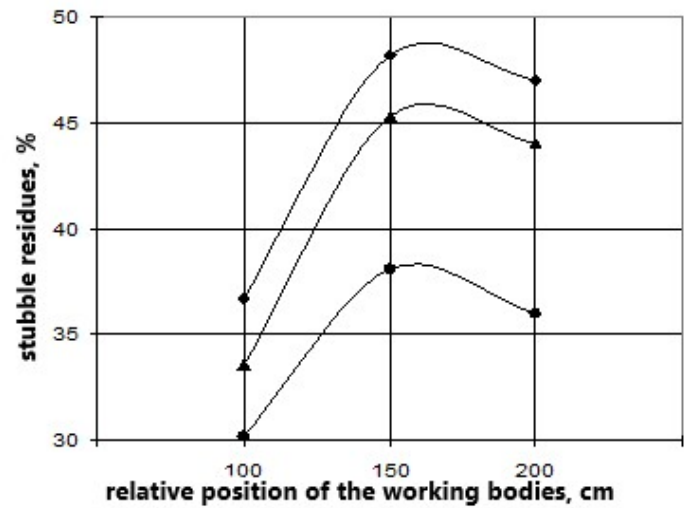

Fig. 6. The degree of incorporation of stubble residues depending on the relative position of the working bodies

$\mathrm{O}$ - bit stroke depth $0,1 \mathrm{~m}$

$\diamond$ - bit stroke depth $0,12 \mathrm{~m}$

$\Delta$ - bit stroke depth $0,14 \mathrm{~m}$

With an increase in the distance from the stalk of the duckfoot to the strut of the loosening working body, an increase in the degree of incorporation of stubble residues into the surface layer is observed: at a distance of $100 \mathrm{~mm}$, the degree of incorporation of stubble residues was $30 \ldots 36.7 \%$, at a distance of $150 \mathrm{~mm}$, the degree of incorporation was $38.1 \ldots 48,2 \%$, at a distance of $200 \mathrm{~mm}$, the degree of embedding was $36 \ldots 47 \%$, which indicates the active influence of the mutual arrangement of the working bodies on the quality and quantity of the created mulching layer (Figure 6).

To ensure the required location of the formed mulching soil layer at a depth of up to $0.14 \mathrm{~m}$, the optimal distance from the duckfoot paw to the rack of the loosening working body is $150 \mathrm{~mm}$. Such a mutual arrangement of the working bodies will allow stubble residues to be embedded in the surface layer in the amount of $48.2 \%$ of the total mass.

After carrying out the planned work, the technological operation of the autumn surface moistureretaining soil cultivation was improved: initially, the soil layer is cut to a depth of $0.10 \mathrm{~m}$ and its high-quality crumbling, then stubble remains are embedded in the surface soil layer with simultaneous subsurface belt loosening to a depth of $0.14 \mathrm{~m}$. For its implementation, a combined working body has been developed, which includes in its design lancet shares and a ripper made in the form of a chisel and mounted directly on a spring rack using a special bracket.

The results of measurements of the volume of soil loosened by the chisel when moving it at one meter along the trajectory of movement with subsequent recalculation to an area of 1 ha showed that with an increase in the width of the installed bit to $0.02 \mathrm{~m}$, the volume of the loosened furrow grows parabolic. A slight decrease in the increase in the volume of the loosened furrow when installing bits with a width of more than 
$0.02 \mathrm{~m}$ is explained by the fact that during the operation of the additional loosening working body, a partial overlap of the made furrows occurs, which grows with an increase in the width of the bit. At the same time, there is a decrease in the height of the wall of not loosened soil separating adjacent furrows, precisely in the place of the greatest accumulation of water. For this reason, there is a rapid overflow of the furrow and the overflow of water into the lower furrow, along the slope, etc. This indicates the need to use a bit with a width of no more than $0.02 \mathrm{~m}$ as an active working body.

When determining the dependence of the change in the volume of loosened soil on the change in the angle of entry of the bit, it was found that with an increase in the angle of entry of the bit of the working body by 5 degrees, the volume of soil loosened by it increases by 2.3 percent. This indicates an insignificant effect of the change in the angle of entry on the volume of the loosened furrow, even though this characteristic has a significant effect on the quality of soil crumbling. Therefore, its value, based on the requirements for the quality of soil crumbling, must be taken equal to 35 degrees.

From the analysis of the data obtained while determining the optimal value of the crumbling angle, the quality of soil crumbling by the loosening working body at values of more than $90 \%$ is observed at crumbling angles from $28^{\circ}$ to $40^{\circ}$ with a maximum at $35^{\circ}$.

\section{Conclusion}

As a result of substantiation of the optimal value of the distance of setting the loosening working body behind the duckfoot, it was found that with an increase in the distance from the stalk of the duckfoot to the rack of the loosening working body, an increase in the degree of incorporation of stubble residues into the surface layer was observed: at a distance of $100 \mathrm{~mm}$, the degree of incorporation of stubble residues was $30 \ldots 36.7 \%$, at a distance of $150 \mathrm{~mm}$, the degree of embedding was 38.1 ... $48.2 \%$, at a distance of $200 \mathrm{~mm}$, the degree of embedding was $36 \ldots 47 \%$, which indicates the active influence of the mutual arrangement of the working bodies on the quality and quantity of the created mulch layer.

To ensure the required location of the formed mulching soil layer at a depth of up to $0.14 \mathrm{~m}$, the optimal distance from the duckfoot paw to the rack of the loosening working body is $150 \mathrm{~mm}$. Such a mutual arrangement of the working bodies will allow stubble residues to be embedded in the surface layer in the amount of $48.2 \%$ of the total mass.

The optimal parameters of the angle of crumbling of duckfoot paws with a loosening working body when cultivating the soil to a depth of $0.14 \mathrm{~m}$ are angle $\alpha 1=$ 350 at a working speed $v=2.24 \ldots 2.26 \mathrm{~m} / \mathrm{s}$, which ensures the quality of soil crumbling up to $95 \%$ at autumn surface moisture-retaining treatment.
This treatment will allow to completely absorb the incoming moisture due to the increased specific absorbing and transporting surface of the qualitatively loosened topsoil layer containing stubble residues distributed throughout the volume of this layer. At the same time, stubble residues provide increased protection of the surface of the treated soil layer from moisture evaporation.

\section{References}

1. N.L. Morris et al., The adoption of non-inversion tillage systems in the United Kingdom and the agronomic impact on soil, crops and the environment. A review, Soil and Tillage Research, 108(1-2), 1-15 (2010)

2. C. Plaza et al., Physical, chemical, and biochemical mechanisms of soil organic matter stabilization under conservation tillage systems: a central role for microbes and microbial by-products in $\mathrm{C}$ sequestration, Soil Biology and Biochemistry, 57, 124-134 (2013)

3. K.H.D. Tiessen et al., Conventional and conservation tillage: Influence on seasonal runoff, sediment, and nutrient losses in the Canadian prairies, Journal of Environmental Quality, 39(3), 964-980 (2010)

4. A. Jordán, L.M. Zavala, J. Gil, Effects of mulching on soil physical properties and runoff under semiarid conditions in southern Spain, Catena, 81(1), 7785 (2010)

5. S.A. Ivanaisky, A.N. Zotov, V.P. Berestov, Development of combined working bodies for surface tillage, Innovative achievements of science and technology of the agro-industrial complex, 392396 (2018)

6. S.A. Ivanaisky, O.M. Parfenov, Working body for pre-sowing soil cultivation, Actual problems of agrarian science and ways of their solution, 364-366 (2016)

7. W. Xiukang, L. Zhanbin, X. Yingying, Effects of mulching and nitrogen on soil temperature, water content, nitrate- $\mathrm{N}$ content and maize yield in the Loess Plateau of China, Agricultural Water Management, 161, 53-64 (2015)

8. C.K. Shedd, E.V. Collins, J.B. Davidson, Labor, power and machinery in corn production, Bulletin, 32(365), 1 (2017)

9. J.A. Andrade, C.A. Alexandre, G. Basch, Effects of soil tillage and mulching on thermal performance of a Luvisol topsoil layer, Foliae Oecologicae, 37(1), 1-7 (2010)

10. D. Hillel, T.T. Kozlowski, Soil moisture and seed germination, Water deficits and plant growth, 3, 6589 (2012) 